\title{
Revisitando o conflito para pensar a prática educativa
}

\author{
Moacir Fernando Viegas ${ }^{1}$ \\ Adriana Janice Lenz ${ }^{2}$
}

\section{RESUMO}

O artigo constitui-se de revisão teórica e reflexão sobre o conceito de conflito e seu significado na realidade atual, em especial na educação, apontando possibilidades de experiências com o mesmo na realidade escolar. O objetivo é compreender o significado dos conflitos sociais, de modo a subsidiar as discussões sobre o tema, assim como estimular a crítica de concepções tradicionais. A base teórica principal do texto é a dialética, entendendo essa teoria como fundamento essencial para pensar as relações sociais em que se configuram as diferentes formas de conflito nos dias de hoje. O texto parte das características básicas do conceito de conflito, onde, destacando as teorias de Durkheim e de Marx, menciona as ideias as quais têm sido associado na prática social. Depois enfoca as relações entre conflito e consenso, priorizando o debate sobre a teoria da solidariedade durkheiminiana. Conclui com uma discussão inicial sobre o conflito na escola na perspectiva da mediação, em que realça a problemática da compreensão das relações sociais de conflito para a construção das práticas educativas.

Palavras-chave: Conflito e Educação. Conflito e Relações Sociais. Mediação de Conflitos.

\section{Revisiting the conflict to think about the educative practice}

\section{ABSTRACT}

The article is made of a theoretical review and a reflexion about the concept of conflict and its meaning in reality nowadays, mainly in

1 Doutor em Educação pela Universidade Federal do Rio Grande do Sul. Pós-doutorado em Psicologia do Trabalho na Universidad Autónoma de Barcelona. Professor adjunto da Universidade de Santa Cruz do Sul, atuando na graduação e na pós-graduação stricto sensu, em educação. Integra o Grupo de Pesquisa Educação, Trabalho e Emancipação. Email: moacirfviegas@gmail.com

2 Mestre em Educação, pela Universidade de Santa Cruz do Sul - UNISC. Orientadora Educacional da Escola Municipal de Ensino Fundamental Professor José Ferrugem. Integra O Grupo de Pesquisa Educação, Trabalho e Emancipação. Email: adrianajlenz@yahoo.com.br 
education, pointing possibilities of experience with it on schools. The main goal is to contribute theoretically to the comprehension of the meaning of social conflicts, in a way to subsidize and stimulate the criticism of traditional conceptions. The main theoretical base of the text is the dialectic, understanding that this theory as an essential foundation to think about the social relationships in which the different forms of conflict are configured nowadays. Coming from the basic characteristics of the concept of conflict, the article focuses, next, on the relations between conflict and consensus, to then discuss about the conflicts in the social relationships and conclude with a initial discussion about the school conflict in the mediation perspective.

Keywords: Conflict and Education. Conflict and Social Relationship. Conflict Mediations.

\section{Revisitando el conflicto para pensarse la practica educativa}

\section{RESUMEN}

El artículo se constituye de revisión teórica y reflexión sobre el concepto de conflicto y su significado en la realidad actual, en especial en la educación, señalando posibilidades de experiencias con el mismo en la realidad escolar. El objetivo es comprender el significado de los conflictos sociales, de modo a subsidiar las discusiones sobre el tema, así como estimular la crítica de concepciones tradicionales. La base teórica principal del texto es la dialéctica, entendiendo esa teoría como fundamento esencial para pensar las relaciones sociales en que se configuran las diferentes formas de conflicto en los días de hoy. El texto parte de las características básicas del concepto de conflicto, en que destacan las teorías de Durkheim y de Marx, mencionando las ideas que se han asociado en la práctica social. Luego enfoca las relaciones entre conflicto y consenso, priorizando el debate sobre la teoría de la solidaridade Durkheim. Concluye con una discusión inicial sobre el conflicto en la escuela en la perspectiva de la mediación, subrayando la problemática de la comprensión de las relaciones sociales de conflicto para la construcción de las prácticas educativas.

Palabras clave: Conflicto y Educación. Conflicto y Relaciones Sociales. Mediación de Conflictos. 


\section{INTRODUÇÃO}

O interesse pelo tema deste artigo tem origem no percurso como orientadora educacional de um de seus autores, numa experiência profissional geradora de questionamentos, dúvidas e inquietudes no enfrentamento dos conflitos na realidade escolar. O transcorrer dessa prática profissional trouxe, inevitavelmente, a convivência com situações de conflito, diante das quais a insegurança quanto à forma mais adequada de administrá-los era uma constante. Soma-se a isso nossa tendência a ver o conflito como algo negativo, reduzindo a atividade de mediação a um trabalho intermediário entre dois sujeitos que discordam.

Nas reuniões e no compartilhamento das angústias com outras profissionais orientadoras, é perceptível em todas a ansiedade diante das situações de conflitos. Frequentemente tais encontros parecem aumentar ainda mais a incerteza, resumindo-se, muitas vezes, a queixas e reclamações. Parte dessa ansiedade decorre do pouco conhecimento teórico que temos a respeito do tema, ficando nosso nível de reflexão limitado aos "achismos" e empirismos.

Confirmamos essa carência teórica entre as entrevistadas na pesquisa que deu origem a este artigo, em que foi comum ouvir as orientadoras educacionais dizerem "o que é mais difícil é a gente se manter atualizada com material de Orientação! Não tem nada teórico em que tu possas te embasar", ou "o material de Orientação é carente; direto da Orientação a gente recebe pouco. É mais ligado às teorias, às práticas da educação como um todo". Tais queixas correspondem ao que encontramos em nossa revisão teórica do Banco de Teses e Dissertações e no Portal de Periódicos da Capes, onde é nítida a pouca produção específica na área da Orientação Educacional.

A prática educativa do especialista precisa estar apoiada no pensamento científico e não no conhecimento imediato. Como afirmam Oliveira, Almeida e Arnoni (2007, p. 60),

O conhecimento imediato explica a realidade por meio de uma abordagem empírica, fruto da nossa impressão primeira, a qual é fixada por meio de estereótipos, analogias e esquemas elaborados sem a menor preocupação de sistematização, organização e problematização da realidade, atravessando sucessivas gerações sem ser questionado. 
Refletir sobre os conflitos na escola não é uma tarefa tão fácil, pois social e culturalmente vivemos uma realidade em que o conflito é compreendido geralmente apenas por um viés negativo. $\mathrm{O}$ tema gera sentimentos de angústia e impotência, tanto pela equipe gestora, em especial os orientadores educacionais, que lidam especificamente com a questão, como pelos professores, o que acaba por colocar em dúvida convicções sobre a ação dos profissionais envolvidos. Entender e enfrentar a necessidade de apropriação teórica dessa problemática para desmistificá-la é tarefa de pesquisadores, da escola e da equipe de profissionais que nela atuam.

Acreditamos que os conflitos podem ser concebidos como potencializadores da aprendizagem, desde que mediados pelo diálogo e pelo debate. Parece-nos necessário, então, compreender a dinâmica dos conflitos e conhecer as possíveis metodologias que podem auxiliar nossa prática. Nesse sentido, buscamos com esse artigo apresentar uma revisão teórica sobre o conceito de conflito, refletindo sobre seu significado na atualidade das relações sociais, em especial no âmbito da educação escolar. O objetivo é compreender o significado dos conflitos sociais, de modo a subsidiar as discussões sobre o tema, assim como estimular a crítica das concepções tradicionais. Para Grinspun (2003, p. 76),

\footnotetext{
Hoje a Orientação Educacional tem o papel da mediação na escola, isto é, ela se reveste de mais um campo na escola para analisar, discutir, refletir com e para todos que atuam na escola, em especial os alunos, não com um tom preventivo, corretivo, mas com um olhar pedagógico.
}

Mas, questionamos: como pode a escola promover a cidadania e o diálogo frente a uma cultura na qual os conflitos são mal compreendidos e interpretados, tornando-se às vezes causas de violência na própria escola? Como os orientadores educacionais poderiam propiciar à comunidade escolar uma postura dialógica, construindo competências para o diálogo, a participação e a cidadania?

A convivência diária com situações de conflito e, sobretudo, a vontade de contribuir com o espaço escolar, oferecendo possibilidades de enfrentamento e mediação, justificam a necessidade de aprofundamento do tema. Encontramos nele a oportunidade de conhecer mais sobre a dialética dos conflitos e os processos de mediação dos mesmos, 
o que, a nosso ver, contribui para a construção de competências necessárias às crianças, adolescentes e jovens nas suas relações interpessoais.

O texto parte das características básicas do conceito de conflito, em que, destacando as teorias de Durkheim e de Marx, menciona as ideias as quais têm sido associado na prática social. Depois enfoca as relações entre conflito e consenso, priorizando o debate sobre a teoria da solidariedade durkheiminiana. Conclui com uma discussão inicial sobre o conflito na escola na perspectiva da mediação, em que realça a problemática da compreensão das relações sociais de conflito para a construção das práticas educativas.

\section{Considerações iniciais sobre o conflito}

A palavra "conflito" tem origem no latim conflictu, que significa choque, combate ou luta. Em sua etimologia, portanto, está presente a ideia de duas partes em oposição. No Dicionário Aurélio, encontramos a seguinte definição: embate dos que lutam; discussão acompanhada de injúrias e ameaças; guerra; luta, combate; colisão, choque (FERREIRA, 1988). Outra definição, do Dicionário de Política, de Norberto Bobbio: "conflito é uma forma de interação entre indivíduos, grupos, organizações e coletividades que implica choques para o acesso à distribuição de bens escassos" (BOBBIO, 1992). E ainda, uma definição muito interessante de Sun Tzu (2000), diz que "o conflito é luz e sombra, perigo e oportunidade, estabilidade e mudança, fortaleza e debilidade. O impulso para avançar e o obstáculo que se opõe a todos os conflitos contém a semente da criação e da desconstrução" (TZU, 2000).

Percebemos, assim, que o termo recebe diferentes definições, que variam de uma conotação negativa e destrutiva a processos de interação contraditórios que oferecem oportunidades não apenas de destruição, como também de construção. É bastante comum a associação do conflito a algo negativo, frequentemente acompanhado de imagens de violência. Porém, sem dúvida, o conflito não pode ser reduzido à violência, que é apenas uma das suas formas de manifestação.

Como categoria sociológica de análise, o conflito ocupa lugar de destaque desde as teorias clássicas. Durkheim (1999) tratou o conflito como uma patologia que deveria ser extinguida do sistema social. Para ele, a implementação funcional da divisão social do trabalho garantiria a interdependência dos sujeitos e a "disciplina social". Assim, essa teoria 
funcionalista encara o conflito como um desajustamento social e acabar com ele seria a única forma de garantir a perfeita harmonia na sociedade.

Já Max Weber (1992) combate a concepção funcionalista com o individualismo metodológico, trazendo a "intencionalidade" dos atores para explicar o conflito, entendido como um processo social típico de todas as sociedades únicas, colocando sempre interesses divergentes em contato.

Do pensamento de Weber surge a teoria sociológica da conflitualidade de Georg Simmel (1983). O autor apresenta o conflito como um novo prisma para a análise das relações sociais, considerando-o como uma forma de interação que está presente em qualquer realidade. Para ele, a vida em sociedade envolve a presença do conflito, já que "ao viver em sociedade o conflito é inerente às múltiplas interações de uns-com-os-outros, contra-os-outros e pelos-outros" que constituem esse viver (SIMMEL, 1983, p. 125).

O autor traz para as relações cotidianas o conflito como promotor de mudanças sociais por meio da desestabilização da harmonização da realidade. Seria possível, então, resolver as causas que distanciam os indivíduos e reestruturar a causa da dissociação, buscando a unidade que fora ameaçada pelos interesses opositores. O conflito seria originado desses interesses opostos, que geram tensão no espaço social, mas que produzem também algum tipo de interação entre os sujeitos na busca de interesses comuns ou na síntese que os interesses opostos podem oferecer. "Dessa forma, com a disputa, se finda a indisposição ou indiferença social e se administra os dualismos divergentes" (SIMMEL, 1983, p. 125-126). Nessa compreensão, observamos a possibilidade de pensar o conflito a partir da administração do pensamento divergente. O potencial positivo e transformador é resgatado através da prática do diálogo e da construção de novos consensos, respeitando-se as diferentes ideias.

Pensamos ser correto entender o conflito como uma forma de interação entre os sujeitos sociais, como um movimento político da sociedade e uma oportunidade de crescimento. É o modo como são vividos que os torna negativos ou positivos, construtivos ou destrutivos.

A história da humanidade nos mostra como os conflitos fazem parte da sociedade e foram o motor das principais conquistas sociais e políticas. Nos primórdios da humanidade, nossos ancestrais nômades mantinham a prática de mediar seus conflitos por meio da convivência na comunidade. A ordem tinha um caráter sacro, não se apresentando 
como imposição de uma autoridade social, mas como uma forma de proteção. Segundo Vasconcelos (2008, p. 22), "vigorava um tipo de direito pré-convencional, revelado, indiferenciado da religião e da moral". As relações eram pouco complexas e fortemente horizontalizadas.

Com a revolução agrícola, as comunidades foram passando de nômades para sedentárias e os mais hábeis e fortes foram acumulando riquezas e apossando-se das terras produtivas, escravizando os povos derrotados. Assim, conforme Vasconcelos (2008, p. 22),

A violência foi convertida em instrumento de poder,
para proteção ou perseguição, a serviço, quase sem-
pre, de grandes proprietários de terras, com apoio
de milícias privadas, com atenuações ou ampliações,
consoante às crenças, mitos e temores religiosos vi-
gorantes. [...] A coercitividade difusa das sociedades
primitivas foi sendo substituída por um direito tradi-
cional, convencional, em que a norma, elaborada por
um poder central, vai constituindo uma "ética da lei",
enquanto outorga de expectativa generalizada de
comportamento.

Mais tarde, a natureza patrimonialista propagou a cultura de dominação, e já no final do feudalismo, com o desenvolvimento do comércio, o poder foi se deslocando dos senhores feudais para os capitalistas mercantis, de soberano para governo e de território para população (VASCONCELOS, 2008, p. 24), mudanças essas que se consolidam a partir do século XVIII, quando nasce a economia política e o capitalismo.

Com a Revolução Industrial, ampliou-se o comércio, a cultura escrita expandiu-se por meio da imprensa e houve um deslocamento da população para cidades cada vez maiores e numerosas. Mais do que isto, ampliaram-se a complexidade e a conflituosidade nas relações sociais.

A partir daí, com os novos modelos institucionais dos Estados Democráticos de Direito, as sociedades modernas foram incorporando a consciência de uma complexidade crescente e atenuando os códigos do poder hierárquico, que então não apresentam mais tanta rigidez. Segundo Vasconcelos (2008, p. 25), passou-se a construir uma circularidade instável entre poder, direito, Estado e cidadania:

As pessoas sociologicamente urbanizadas vão se tornando avessas às hierarquias tradicionais, pois o amplo acesso ao conhecimento não é compatível com as posturas de imposição unilateral. Ao atenuar 
as hierarquias patrimonialistas, a "Revolução dos Conhecimentos" deflagra ondas emancipatórias. Paralelamente à emancipação feminina, avança, na consciência moral e política do povo, um sentimento-ideia de igualdade, que se expressa na forma de um movimento emancipatório, insurrecional.

Para o mesmo autor, "essa visão integradora enfrenta uma contemporaneidade desafiada a lidar com o artificialismo da vida urbana" (VASCONCELOS, 2008, p. 25). Desta maneira, a característica da era dos conhecimentos, com seu aspecto positivo e libertário, foi transformada em tédio, impaciência, revolta e criminalidade.

Diante de uma sociedade onde ainda prevalece o conflito como uma forma de manter a hierarquia e a desigualdade, eliminando o conflito muitas vezes pelo uso da força e da violência, enfrenta-se o desafio de construir uma forma consensual de administrá-los.

\section{Conflito e consenso}

Refletir sobre o conflito implica pensar também sobre o consenso. Durkheim, como já destacado, contribuiu para a análise da sociedade abordando diferentes processos sociais, entre eles o conflito e o consenso. Preocupado em descobrir como os indivíduos constituem a sociedade e o consenso em seu interior, elaborou a teoria da solidariedade como norteadora de suas reflexões. Conforme Lucena (2010), esta teoria apresenta duas categorias fundamentais, a solidariedade mecânica e a solidariedade orgânica, que assim este autor sintetiza:

Na solidariedade mecânica os homens estão unidos a partir da semelhança de valores expressos na religião, tradição ou sentimento comum. Este é um tipo de solidariedade à qual a sociedade tem coerência porque os indivíduos ainda não se diferenciam. A solidariedade orgânica, por sua vez, é diferente da solidariedade mecânica. Solidariedade orgânica é aquela em que o consenso resulta de uma diferenciação, ou se exprime por seu intermédio. Dentro desta concepção, os homens não se assemelham, sendo diferentes entre si. A união desses homens só é possível a partir da dependência que um tem do outro para realizar alguma atividade social. (LUCENA, 2010, p. 304). 
Seguindo o pensamento do autor, Durkheim traz um ponto fundamental em sua teoria, que é a formação da consciência coletiva, que existe somente a partir das crenças presentes nas consciências individuais: "nas sociedades dominadas pela solidariedade mecânica, a consciência coletiva abrange a maior parte das consciências individuais" (LUCENA, 2010, p. 297). Já quando impera a solidariedade orgânica, "ocorre uma redução da esfera da existência que cobre a consciência coletiva, um enfraquecimento das reações coletivas contra a violação das proibições e, sobretudo, maior na interpretação individual dos imperativos sociais" (LUCENA, 2010, p. 304).

Fica claro na teoria durkheimiana a valorização do coletivo em detrimento do individual, do consenso em detrimento do dissenso, em que é proposta, indiretamente, uma acomodação dos interesses individuais pelo equilíbrio do coletivo, em que a defesa da unidade social, da não cisão - que causaria o desequilíbrio social - é o ponto que prevalece. Conforme Oliveira (2001, p. 59),

Para Durkheim, a organização social só é possível me-
diante o consenso ou a consciência coletiva, e a har-
monia na sociedade inicia-se com a solidariedade e
com as regras morais estabelecidas pelos indivíduos,
a partir do momento em que existem valores com-
partilhados por todos.

Guisard e Junior (2011) concordam que em Durkheim há o predomínio da sociedade sobre o indivíduo, da ideia de consenso, de unidade e de ordem social, afirmando que essa concepção serve à sustentação ideológica da formação de sujeitos socialmente submissos ao Estado, valorizando as forças coletivas que retiram do homem suas paixões e seu ser individual. Para eles, "Durkheim propõe a internalização dessas forças coletivas, por exemplo, através de uma educação moral" (GUISARD; BARRETO JUNIOR, 2011, p. 69).

Na concepção de Durkheim, se os valores de uma sociedade se debilitam, a sociedade fica ameaçada de desintegração. Conforme Lucena (2010, p. 298), "na medida em que as sociedades modernas se fundamentam na diferenciação, torna-se indispensável que o trabalho que cada um exerce corresponda a seus desejos e aptidões", acrescentando que "o problema das sociedades modernas é as relações entre os indivíduos e o grupo", pois "o homem tornou-se por demais consciente de si mesmo para aceitar cegamente os imperativos sociais. 
Desse modo, Durkheim defendia a necessidade de uma disciplina que só a sociedade pode impor, e é aí que a educação exercerá um papel fundamental, como instituição que objetiva essencialmente socializar os indivíduos. A educação é para a sociedade o meio pelo qual ela prepara ou adapta, nas crianças, as condições fundamentais para a sua própria existência, o que, no final do século XIX e início do XX, dava sustentação ideológica à formação de força de trabalho para as fábricas. Segundo Lucena, na perspectiva durkheimiana,

\footnotetext{
É preciso constituir através da educação os estágios originais que não estão formados na criança. [...] Há que sufocar e cortar a sua curiosidade, sua mobilidade, vivacidade e imaginação. Há que instigar a obediência que o dispositivo pedagógico transformará em espírito de disciplina. (LUCENA, 2010, p. 302).
}

Neste sentido, a disciplina visa atuar como um instrumento moral. A ausência de disciplina produziria confusão e sofrimento de não saber o que é o bem e o mal, o certo e o errado, o lícito e o ilícito. Numa turma de alunos bem disciplinada não haveria confusão, mas consenso.

As ideias de Durkheim nos parecem questionáveis, na medida em que essa concepção de consenso é acompanhada da necessidade de acomodação dos sujeitos, de sua conformação à ordem social. Em muitos casos de conflito, temos utilizado a velha frase "a maioria vence" e isso é optar pela consciência coletiva em detrimento da individual para manter a ordem. Pensemos em quantas vezes já fizemos isso na escola, a fim de manter a organização, o equilíbrio e a harmonia. Fomos e talvez ainda sejamos instrumentos reforçadores de consenso baseados nessas ideias. Que posicionamento nós temos diante dos pensamentos divergentes? Minimizamos? Desconsideramos? Ou trazemos para o enriquecimento da consciência do grupo? Como reagimos diante da indisciplina? Refletimos sobre o que ela traz ou apenas "forçamos" a adaptação do aluno indisciplinado aos padrões sociais?

\section{Os conflitos nas relações sociais}

As pessoas são diferentes, têm opiniões, crenças e valores distintos. Assim, é natural que quando nos encontramos uns com os outros, os conflitos apareçam. Podemos dizer que os conflitos são inerentes às relações sociais. 
No pensamento marxista, as lutas de classes constituem o conflito social básico da sociedade. E a sociedade é o lugar de um conflito entre opressores e oprimidos, qualquer que seja a época considerada. $\mathrm{E}$ na raiz desse conflito está a apropriação privada dos meios de produção, sob a qual subjaz a exploração e a pobreza dos que não têm os meios de produzir sua subsistência e o enriquecimento dos que exploram sua força de trabalho.

Para Marx e Engels (1999), a história de toda a sociedade é a história de lutas de classes. Dessas lutas históricas surgiram duas grandes classes sociais que hoje se enfrentam: a burguesia e o proletariado. Segundo os autores, "a história da indústria e do comércio é apenas a história da revolta das modernas forças produtivas contra as modernas relações de produção, contra as relações de propriedade que são as condições de vida da burguesia e da sua dominação" (MARX; ENGELS, 1999, p. 17). Dessa forma, o proletariado se desenvolve na mesma medida em que a burguesia e o capital. Para os autores, a luta de classes, que se manifesta por meio dos conflitos e embates políticos e sociais, é o motor do desenvolvimento das sociedades ao longo da história.

Desta maneira, as transformações históricas foram precedidas do surgimento de interesses e necessidades que entraram em conflito com os interesses e necessidades já existentes. É a partir desta luta entre interesses distintos, por vezes antagônicos, que ocorre a transformação da vida social e econômica.

As lutas sociais, que incluem a busca pelo poder, pela riqueza, pelo prestígio e pelos direitos, são constantes nos grupos sociais que constituem a sociedade e se configuram como parte fundamental do desenvolvimento e crescimento de qualquer sistema familiar, social, político e organizacional.

Mas os conflitos ocorrem no mundo todo em que se confrontam os interesses entre dois ou mais grupos distintos de indivíduos ou de governos. As causas destes confrontos são complexas, resultantes de processos históricos, políticos, étnicos ou religiosos e culturais. Também a busca pela manutenção ou por novos direitos civis e políticos acaba por gerar muitos dos conflitos que acompanhamos através da mídia e que agora chegam até nós de modo quase "instantâneo" pelas redes sociais. As inúmeras fontes de conflito são assim descritas por Nascimento e El Sayed (2002, p. 51): 
[...] direitos não atendidos ou não conquistados; mudanças externas acompanhadas por tensões, ansiedades e medo; luta pelo poder; necessidade de status; desejo de êxito econômico; exploração de terceiros (manipulação); necessidades individuais não atendidas; expectativas não atendidas; carências de informação, tempo e tecnologia; escassez de recursos; marca das diferenças culturais e individuais; divergência de metas; tentativa de autonomia; emoções não expressas/inadequadas; obrigatoriedade de consenso; meio-ambiente adverso e preconceitos.

Para Fernandes (1993, p. 787), "as sociedades vivem em estado de permanente conflitualidade, tanto mais acentuada quanto mais complexas se apresentam", e sua compreensão exige um grande esforço teórico. Se formos analisar, por exemplo, os conflitos sociais religiosos, é necessário adentrarmos na cultura que os envolve, pois, caso contrário, será muito difícil fazer uma leitura adequada do seu funcionamento. Segundo o autor, sendo inerentes à sociedade e sua existência, o aparecimento dos conflitos demonstra sinais de vitalidade da atividade coletiva. Acrescenta que as sociedades que erradicam as lutas sociais são sociedades estagnadas (e, a nosso ver, totalitárias) e que "não há atividade coletiva sem mudança, do mesmo modo que não existe vida social sem antagonismos" (FERNANDES, 1993, p. 790).

Desta maneira, podemos pensar que assim como o conflito gera a mudança, a mudança também gera novos conflitos, e assim sucessivamente, sendo isso o que faz com que a sociedade se desenvolva. Para o mesmo autor, "o conflito é imputável, antes de mais, nas sociedades ocidentais, à própria prática democrática. Deriva, desde logo, da afirmação do direito à diferença, como elemento constitutivo da democraticidade" (FERNANDES, 1993, p. 790), a qual não possui identidade com a homogeneização e o igualitarismo. No estímulo e fomento das diferentes vozes, as sociedades democráticas acabam gerando alguma forma de conflitualidade. Assim, é preciso que pensemos a diversidade de pensamentos, ideias e práticas não como formas de busca pela igualdade, mas como possibilidades de acesso democrático a direitos sociais.

Seguindo ainda o pensamento do autor (FERNANDES, 1993, p. 790), "as sociedades estão longe de constituírem espaços totalmente integrados. Estão constantemente em ação processos de diferenciação que levam ao afastamento de indivíduos e de grupos". Porém, este dis- 
tanciamento, por si só, não conduz à conflitualidade: "a conflitualidade surge com a consciência despertada para a existência da desigualdade ou para a recusa do estigma.

Por outro lado, a sociedade institucionaliza os conflitos para controlá-los, o que acaba conseguindo na maioria das vezes, estabelecendo suas regras e suas soluções. Desse modo, as instituições tendem a amortecer e regular os conflitos, cumprindo um papel que o autor chama de "válvula de segurança, levando os atores sociais a deslocarem os seus objetivos ou a diminuírem a intensidade da ação" (FERNANDES, 1993, p. 794). No entanto, ressalta ele que o exercício do sufocamento de toda a agressividade e repressão de manifestações legítimas resultam na destruição de aspirações e à insatisfação, terminando por produzir situações próximas à explosão e à ruptura.

A desmobilização e a institucionalização acabam sendo ferramentas muito eficazes para enfraquecer e ocultar os conflitos sociais. É através desses instrumentos que os governos e as organizações conseguem manter o controle sobre os movimentos sociais e políticos da sociedade.

Entendemos que em sua tarefa de desenvolver o ensino e a aprendizagem, a escola está implicada, juntamente com a comunidade escolar, no gerenciamento dos conflitos que fazem parte do seu cotidiano. A escola é uma instituição em que se processam mediações. É o local onde as crianças, os adolescentes, os jovens e toda a comunidade escolar aprendem a lidar com os conflitos do dia-a-dia. Pensando assim, fazemos alguns questionamentos: como lidamos com os conflitos no contexto escolar? Como percebemos e negociamos com os interesses dos sujeitos? Qual o fazer político da escola diante disso?

Cada sociedade cria suas próprias formas de normalizar e regular as relações sociais e a convivência (as leis, os códigos, as normas), delimitando assim até onde vai a liberdade de cada um. Se há algum tempo a força física e a violência eram vistas como a única forma possível de resolver divergências culturais e políticas, nos dias atuais a compreensão é que é possível enfrentar essa tarefa por meio da mediação dos conflitos, tomando-os como forma de capacitar os sujeitos a lidarem com as divergências de maneira a construírem-se a si e a sociedade.

A nosso ver, a prática de mediação de conflitos é necessária aos sujeitos escolares. O estímulo a autoridades fundadas no autoritarismo só pode levar a uma sociedade amordaçada, onde poucos têm voz. A construção de uma sociedade melhor depende de uma autoridade 
construída pela capacidade de diálogo e pela gestão de conflitos, que reconheça a dimensão política da prática escolar, o que demanda da escola o exercício da autoridade com justiça e abertura para o diálogo, onde os conflitos sejam mediados visando à emancipação e autonomia dos sujeitos.

Mas, quando ocorrem os conflitos na escola, que autoridade é usada para administrá-los? Em que medida usamos nossa capacidade de diálogo nestes momentos? Ameaçamos ou agimos como mediadores de um processo? Analisamos, com os sujeitos envolvidos, o problema e as possibilidades de resolução? Quais as razões que damos para que nossos alunos façam acordos? Enfim, quais os rumos que damos aos conflitos na escola?

\section{Os conflitos na escola na perspectiva da mediação}

As pesquisas têm trazido para nossa reflexão novas formas de compreensão e entendimento dos conflitos sociais e, por consequência, dos conflitos escolares. Para Quera (2005), apesar de produzirem em nós sentimentos de medo, desconfiança e incapacidade, eles também nos impelem à necessidade de posicionamento no sentido de buscar elementos que nos permitam superá-los, o que implica reconhecê-los como oportunidades de aprender. $\mathrm{O}$ acolhimento do conflito nos possibilita acesso a informações até então desconhecidas e que nos ajudam a avançar. Algo que encontrava em nós ou nos outros um determinado entendimento é colocado em discussão e novas informações e entendimentos são produzidos.

O conflito decorre de expectativas, valores e interesses diferentes. Embora seja contingência da condição humana, numa disputa conflituosa costuma-se tratar a outra parte como adversária e inimiga. Nessa forma de enfrentar divergências, "cada uma das partes tende a concentrar todo o raciocínio e elementos de prova na busca de novos fundamentos para reforçar a sua posição unilateral, na tentativa de enfraquecer ou destruir os argumentos da outra parte" (VASCONCELOS, 2008, p. 19). Esse modo de agir estimula as polaridades e dificulta a percepção do interesse comum.

Para o autor, uma relação totalmente consensual é impossível e mesmo nas relações sociais mais afetivas e próximas o conflito se faz presente. Ele ressalta a originalidade, assim como a particularidade das experiências de cada sujeito. Nesse sentido, é fundamental que os indivíduos tenham consciência de que o conflito faz parte da condição 
humana, pois, sem essa consciência, a tendência é ignorá-lo ou mesmo demonizá-lo.

A nosso ver, esta é uma questão central: o conflito pode ser percebido como possibilidade de mudança, de transformação, de aceitação das diferenças pessoais e de pensamentos divergentes. Na teoria de Freire, estaríamos falando na perspectiva de uma "ação dialógica", não no sentido de eliminar as tensões, mas de saber que os conflitos são constitutivos do humano. Nas palavras do autor,

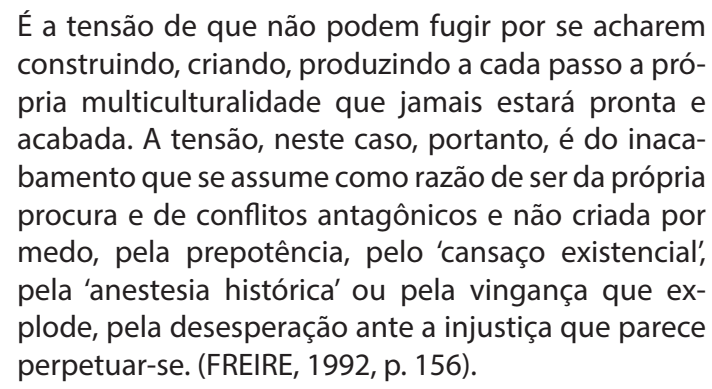

Preocupado com a emergência de uma cultura da violência, Freire (2011) afirma que precisamos, desde muito cedo, formar as crianças na "Cultura da Paz". Uma cultura de desvelamento e não de ocultação, estimulando a colaboração, a justiça, a solidariedade e a tolerância entre os diferentes. Pensamos que essa afirmação do Patrono da educação brasileira serve como o principal traço definidor de um trabalho de gestão dos conflitos na área da educação, o qual pode ser desenvolvido no processo da mediação.

Uma condição essencial nesse processo é que na interação entre fala e escuta entre os sujeitos haja o que Freire (2011) chama de "disciplina do silêncio". É preciso que os sujeitos saibam escutar, demonstrando isso no controle do seu próprio exercício do direito de se expressar e no gosto de dizer a sua palavra. Perceber o diálogo como condição para a mediação dos conflitos escolares é compreender uma cultura em que o ser humano é primordial e que existem nele mesmo as condições e capacidades para uma convivência mais fraterna e pacífica.

Também para Burguet $(2005$, p. 42) somos produtores de conflitos. Muitos deles acabam por não se resolver e, aceitando-os, temos que aprender a conviver de forma pacífica. Na medida em que, como diz o autor, as situações de conflito dão origem aos processos de crescimento, está aí a razão para encará-las positivamente, como instrumentos de 
mudança, de desafio para desenvolver respostas novas e soluções criativas e não meramente como processos que tenham que se conformar à realidade.

Acreditamos que educar para a diversidade é uma forma de mediar culturas, formando para a cidadania e para a pluralidade. É isso que faz humana a sociedade e que nos enriquece cotidianamente. Ainda para Burguet (2005, p. 46-47),

Às vezes, conviver harmonicamente comporta saber fazer acordos para superar a discórdia em que vivemos com os outros e frequentemente com nós mesmos. [...] Por isso muitas vezes devemos enfrentar, em primeiro lugar, tantos ruídos ensurdecedores que nos contaminam para transformá-los em sons harmônicos. Na pedagogia devemos trabalhar o silêncio, ensaiar o silêncio. Voltar ao que é mais natural na pessoa.

Para Nazareth (2009), a tensão desencadeada pelas crises que provocam os conflitos deve ser administrada com cautela por meio da mediação. Ela é a responsável por transformar situações que possam representar perigo em oportunidades de mudança. Nesse sentido, entendemos que, independentemente das formas como se apresentam, encarar os conflitos como oportunidade é dar uma nova chance ao ser humano, é possibilitar que a sociedade possa caminhar para uma visão dialética do processo de desenvolvimento social e político.

Refletir sobre a questão dos conflitos na escola atualmente não é uma tarefa fácil, pois, social e culturalmente, vivemos uma realidade que segue propagando uma concepção da qual predominam aspectos negativos, que devem, portanto, ser evitados. Pesam ainda sobre nós os anos de ditadura militar, a pouca experiência em democracia e a permanência da cultura da violência, "do olho por olho, dente por dente. Estas questões, como não poderia deixar de ser, refletem-se também no ambiente escolar.

Assim, entender e enfrentar a concepção negativa do conflito passa a ser tarefa da escola. Ela, na verdade, se vê forçada a fazer essa análise para poder, na medida de suas possibilidades, não apenas desmistificar as concepções equivocadas, mas também desenvolver formas adequadas de administração dos conflitos, no sentido de potenciá-los como fomentadores da aprendizagem. 
Mas como pode a escola promover essa nova visão dos conflitos frente a uma cultura na qual eles são mal compreendidos e mal vistos, tornando-se, muitas vezes, as principais causas da violência? Para isso, pensamos que é importante introduzir na instituição escolar novos conceitos de administração positiva de conflitos. Vemos como necessário aproximar o conflito da ciência e desenvolver a arte de aplicá-la a educadores, professores, estudantes, profissionais e a todas as pessoas interessadas em enfrentar as situações conflituosas, melhorando suas relações consigo mesmas e com seus semelhantes.

Segundo Burguet (2005, p. 42),

Os alunos necessitam entender os conflitos, aprender formas alternativas para resolvê-los e buscar soluções que sejam satisfatórias para todos. Aí está o eixo fundamental para desfazer o intrincado complexo de razões que os conflitos costumam provocar: partir da base de que sua resolução e/ou gestão não supõe um ganhador e um perdedor; partir da base de que os dualismos apenas se tornam fonte de novos conflitos futuros e de fundamentalismos de todo tipo; partir da base de que uma boa prevenção se inscreve em uma boa gestão dos conflitos presentes.

Por inúmeras vezes nos deparamos com situações em que visualizamos posturas que potencializam a atitude competitiva realçada pelo autor, em que um deve ganhar e o outro deve perder, e não nos damos conta de que é possível e necessário, nessas situações, fazer uma intervenção mediadora com objetivos pedagógicos, mesmo porque, como afirma Burguet (2005), a paz não vem sozinha.

Marimon e Vitarrasa (2005) destacam outro componente importante do conflito, que são as emoções. Para as autoras, certa carga emocional sempre acompanha os conflitos e às vezes constituem sua principal causa. Desta maneira, pensar em uma forma pedagógica de trabalhar com os conflitos na escola é chamar para o diálogo aqueles sujeitos que estão envolvidos emocionalmente e que, assim, têm dificultado o alcance de uma consciência crítica diante de determinada situação. A emoção não trabalhada ou não mediada, por vezes, pode cegar os sujeitos, sendo necessário retirá-los do plano imediato e aproximá-los do plano mediato.

Quando meninos e meninas já podem identificar emoções e descobrir formas de superar aquelas que 
são desagradáveis, é possível aplicar esses conhecimentos a situações reais que se apresentem na vida escolar. O exercício dessas habilidades proporciona a meninos e meninas uma grande confiança. [...] O conhecimento das emoções, de que situações as provocam e de como manejá-las é indispensável para aprender a resolver conflito [...]. (MARIMON; VITARRASA, 2005, p. 70).

Se pensarmos que emoções e conflitos acompanham um ao outro, concluímos que eles podem aproximar-se positivamente quando perpassados por uma consciência crítica dos sujeitos, pois a emoção que os separa é a mesma que os aproxima. Narrar e escutar são os exercícios básicos da mediação de conflitos. É a habilidade do diálogo que aparece aqui como um importante elemento desse processo de mediação pedagógica. Para Danti (2005), não há mediação sem comunicação.

Conflitos constituem oportunidades de aprendizado para os alunos, para os professores e toda a comunidade escolar, onde as "brigas" que ocorrem precisam ser percebidas como pistas para situações que devem ser trabalhadas. As salas de aula livres de desavenças é que são incomuns. Além disso, o professor não deve ter pressa para resolver a desavença. Conflitos também ensinam e mais importante que solucionar a discórdia é a maneira de encará-la. O maior desafio é não tomar partido, pois, quando isso ocorre, um lado sempre se julga injustiçado e a situação tende a se repetir.

As novas formas de pensar os conflitos nos ajudam a compreender a dinâmica das relações interpessoais e nos possibilitam perceber as mediações pedagógicas que eles carregam (VASCONCELOS, 2008). Nas sociedades complexas como as atuais, prevalecem os aspectos relacionais, os quais exigem uma abordagem também mais complexa dos conflitos. Exigem que se ampliem os espaços para soluções emancipatórias e dialógicas nas disputas e na sua gestão.

Conforme Marimon e Vitarrasa (2005), é um equívoco acreditar que educar para paz pressupõe a erradicação do conflito, pois, como um fenômeno característicos das relações humanas, sua eliminação é impossível. Para a autora, a negatividade dos conflitos está justamente na forma violenta como são vividos. Daí que, segundo ela, educar para paz seja educar para aprender a enfrentar os conflitos de forma não violenta, proporcionando o desenvolvimento de habilidades com esse fim. 
Desta maneira, a mediação pedagógica e dialética de conflitos pode fortalecer a escola como um espaço político-pedagógico, formador de sujeitos políticos e críticos, que exercitam o diálogo nas situações de crise e promovem a mediação entre as partes. Por estarmos implicados na construção de uma sociedade democrática, necessitamos transformar o espaço escolar em um espaço de educação para a diversidade, para o diálogo, a participação e a liberdade.

\section{Considerações finais}

Não resta dúvida de que vivemos tempos conflituosos na sociedade como um todo e, em particular, na realidade escolar, que já há décadas vê questionados seus pressupostos básicos. Especificamente na realidade brasileira, avizinham-se momentos de tensão, repletos de conflituosidade, visto que algumas questões que se pensavam consensuadas voltam à discussão, e de uma maneira que colocam em xeque até mesmo as relações democráticas, em que pese o muito que precisamos avançar na construção das mesmas.

De todo modo, devemos seguir avançando. Com grande frequência, as escolas são notícia nos meios de comunicação e nas redes sociais, nos quais se fazem presentes episódios de violência e conflito. Isso acaba causando certo alarme social e exige de nós, educadores, em especial os orientadores educacionais, uma resposta pedagógica mais qualificada e melhor conduzida. Essa realidade requer uma mudança na prática docente e na formação dos professores e gestores escolares, para que seja melhor administrada. Parece ser cada vez mais necessária a formação dos educadores no conhecimento sobre os conflitos e nas suas formas de gestão.

O modo como gerimos os conflitos na escola indica sobre quais bases estamos edificando a sociedade que queremos: com diálogo e participação ou com imposição e exclusão dos envolvidos? A ideia norteadora deste artigo foi provocar o repensar sobre o que temos entendido sobre os conflitos e de que formas, nós, orientadores educacionais e professores, temos proporcionado em nossas escolas espaços para a sua mediação.

Pensamos que administrar situações de conflito com atitudes pacíficas, tomar decisões saudáveis e respeitosas, manter boas relações interpessoais, são aquisições que os princípios da mediação pe- 
dagógica e dialética podem proporcionar à comunidade escolar. Desta maneira, talvez seja possível capacitar os sujeitos envolvidos, a fim de que provoquem mudanças na escola e a transformem em um espaço democrático, onde se possa vivenciar os valores da cidadania e da solidariedade.

\section{Referências}

BOBBIO, Norberto; MATTEUCCI, Nicola; PASQUINO, Gianfranco. Dicionário de política. 4. ed. Brasília: EDUnB, 1992.

BURGUET, Marta. Diante do conflito... Uma aposta na educação. In: VINYAMATA, Eduard (Org.). Aprender a partir do conflito: conflitologia e educação. São Paulo: Artmed, 2005, p.41-49.

DANTÍ, Fina. Vida e conflito: narração de uma experiência com resolução de conflitos e mediação em uma escola de ensino médio. In:VINYAMATA, Eduard (Org.). Aprender a partir do conflito: conflitologia e educação. São Paulo: Artmed, 2005, p.85-96.

DURKHEIM, Émile. Método para determinar essa função. In: DURKHEIM, Émile. Da divisão do trabalho social. 2. ed. São Paulo: Martins Fontes, 1999, p. 32-37.

FERNANDES, António Teixeira. Conflitualidade e movimentos sociais. Análise Social. v. 28, p. 787-828, 1993. Disponível em:http://analisesocial. ics.ul.pt/documentos/1223292608S8kUR1qx0Wa77QV4.pdf. Acesso em: 14 fev. 2016.

FREIRE, Paulo. Pedagogia da autonomia: saberes necessários à prática educativa. São Paulo: Paz e Terra, 2011.

FREIRE, Paulo. Pedagogia da esperança. Rio de Janeiro: Paz e Terra, 1992.

GRINSPUN, Mírian Paula Sabrosa Zippin (Org.). A prática dos orientadores educacionais. São Paulo: Cortez, 2003.

GUISAR, Luís Augusto Mola; BARRETO JUNIOR, Irineu Francisco. Augusto Comte e Émile Durkheim: uma sociologia "apaziguadora". FMU 
Direito. São Paulo, v. 25, n. 35, p. 64-72, 2011. Disponível em:http:// revistaseletronicas.fmu.br/index.php/RMDIR/article/view/146. Acesso em: 13 abr. 2016.

FERREIRA, Aurélio Buarque de Holanda. Novo Dicionário Aurélio. Rio de Janeiro: Editora Nova Fronteira, 1988.

LUCENA, Carlos. O pensamento educacional de Émile Durkheim. Revista HISTEDBR On-line. Campinas, n. 40, p. 295-305, 2010. Disponível em: https://periodicos.sbu.unicamp.br/ojs/index.php/histedbr/article/ view/8639820. Acesso em: 17 mar. 2016.

MARIMON, Montserrat Moreno; VILARRASA, Genoveva Sastre. Conflitos e emoções: uma aprendizagem necessária. In: VINYAMATA, Eduard (Org.). Aprender a partir do conflito: conflitologia e educação. São Paulo: Artmed, 2005, p.41-49.

MARX, Karl; ENGELS, Friedrich. Manifesto do Partido Comunista. 9. ed. Petrópolis: Vozes, 1999.

NASCIMENTO, Eunice Maria; EL SAYED, Kassem Mohamed. Administração de conflitos. In: Gestão do Capital Humano. Coleção Gestão Empresarial - FAE Business School. Curitiba: Gazeta do povo, 2002, v. 5.

NAZARETH, Eliana Riberti. Mediação: o conflito e a solução. São Paulo: Arte Paubrasil, 2009.

OLIVEIRA, Edson Moreira; ALMEIDA, José Luís Vieira de; ARNONI, Maria Elisa Brefere. Mediação dialética na educação escolar: teoria e prática. In: Ensino e aprendizagem dos limites: da lógica formal à necessidade da dialética. São Paulo: Loyola, 2007, p. 19-74.

OLIVEIRA, Rita de Cássia da Silva (Org.). Sociologia: consensos e conflitos. Paraná: UEPG, 2001.

QUERA, Pilar. O conflito: escutar, aprender e criar. In: VINYAMATA, Eduard (Org.). Aprender a partir do conflito: conflitologia e educação. São Paulo: Artmed, 2005. p.125-140.

SIMMEL, Georg. A natureza sociológica do conflito: conflito e estrutura do grupo. In: MORAES FILHO, Evaristo (Org.). Simmel. São Paulo: Ática, 1983. 
TZU, Sun. A Arte da Guerra. Porto Alegre: L\&PM, 2000.

VASCONCELOS, Carlos Eduardo. Mediação de conflitos e práticas restaurativas. São Paulo: Método, 2008.

WEBER. Max. Conceitos sociológicos fundamentais: metodologia das ciências sociais. Campinas: Cortez/Unicamp, 1992.

Recebido: novembro/2018

Aceito : Fevereiro /2019 